\title{
Heat Transfer using Nanofluid
}

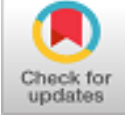

\author{
Jodh Singh, Munish Gupta, Rajesh Kumar, Harmesh Kumar
}

\begin{abstract}
Latest trend of miniaturization of thermal systems, calls for the improvement in their efficiency. Nanofluid contains the nanoparticles having large surface area and improves the thermal efficiency. This enhancement is the function of different mechanisms and parameter. This paper explores the heat transfer nature of nanofluids by addressing the experimental studies available in literature and conducting an experimental study using water based Copper oxide nanofluids. Nanoparticles were characterized by $X$-ray diffraction analysis and Field Emission Scanning Electron Microscopy to confirm the material, size and morphology of the nanoparticles. Thermal conductivity analysis has been performed at $30^{\circ} \mathrm{C}, 40^{\circ} \mathrm{Cand} 50^{\circ} \mathrm{C}$ with $0.1 \%, 0.5 \%$ and $1 \%$ concentration by weight. Mechanism of agglomeration, concentration and size of particles are found to be more significant in affecting the heat transfer. The maximum enhancement of $22.9 \%$ in thermal conductivity is found in case of $1 \%$ weight concentration nanofluids consisting of small size (20nm) nanoparticles at temperature of $50^{\circ} \mathrm{C}$.
\end{abstract}

Keywords: heat transfer, temperature, volume concentration,

\section{INTRODUCTION}

Colloidal suspensions of solid nanoparticles in base fluids are known as nanofluids [1]. Nanoparticles like nanocomposites, nanocrystalline materials, carbon nanotubes (CNT) and ceramic particles etc. and conventional liquids like water, engine oil etc. may be used to synthesize nanofluids. One step and two step methods are meant for small and large scale synthesis respectively. The ultrasonication and magnetic stirring of mixture may be used to get even, stable and durable suspension. Surfactants or functionalized nanoparticles may also be added for increasing stability of nanofluid, if required. Size in nanoscale and large specific area of nanoparticles show higher thermal conductivity, uniformity along with obstruction in flow channel and stability of suspension than that of mixtures consisting of fluids and micro-sized or macro-sized solid particles. They also show minimum

Revised Manuscript Received on December 30, 2019.

* Correspondence Author

Jodh Singh*, Assistant Professor, SSBUICET, PU, Chandigarh, India. jodhme@gmail.com

Munish Gupta, Associate Professor, GJUST, Hissar, Haryana, India. mcheeka1@gmail.com

Rajesh Kumar, Assistant Professor, UIET, PU, Chandigarh, India. rajeshmadan@gmail.com

Harmesh Kumar, Professor, UIET, PU, Chandigarh, India. harmesh@pu.ac.in

(C) The Authors. Published by Blue Eyes Intelligence Engineering and Sciences Publication (BEIESP). This is an open access article under the CC BY-NC-ND license (http://creativecommons.org/licenses/by-nc-nd/4.0/) nanofluids, clusters.

clogging and abrasion in flow passages. Heat transfer is through conduction as well as convection. To get maximum heat transfer at constant temperature potential or surface area, value of coefficient of heat convection may be increased which further depends upon the fluid properties, velocity and surface geometry. These days, the research is focused on the enhancement of cooling rate by altering the fluid properties. However, agglomeration is a major problem in the analysis of nanofluids. In this process the colloidal particles mutually interact and form agglomerates or clusters in dispersed medium. They form clusters of small particles by combining with each other which settled down due to gravity and decrease the shelf life of nanofluids. Nanofluids have been primarily used in coolant for heat transfer systems like heat exchangers, electronic system and radiators etc. Now days, hybrid nanofluids are gaining more popularity. Hybrid nanofluids are obtained by dispersing nanoparticles of at least two different materials in common base fluid in order to get the advantages of materials as a single material can not possess all the desirable properties. This paper is an attempt to explore heat transfer nature of nanofluids by addressing experimental studies based on properties, mechanisms and factors which influence the heat transfer process.

\section{THERMOPHYSICAL PROPERTIES}

\section{A. Thermal conductivity}

It is the property by virtue of which nanofluids conduct heat. It depends upon various factors like temperature, size, concentration, surface area and shape of nanoparticles. Transient hot wire method is precise and less time consuming method to measure thermal conductivity. Vallejo et al. [2] reported that higher temperature results in enhancement of thermal conductivity. Nikulin et al. [3] reported that thermal conductivity increase with increase in particle concentration.

\section{B. Specific heat}

It is the amount of heat needed to increase the temperature of $1 \mathrm{gm}$ of nanofluid by $1^{\circ} \mathrm{C}$. It is linked with heat storage or heat transfer. Specific heat of base fluids is increased when nanoparticles are added. It can be estimated by using a relation given by Xuan and Roetzel [4]. It is measured by using Differential Scanning Calorimeter (DSC) or simple calorimeter.

\section{Viscosity}

It is the internal resistance to the flow of nanofluids which depends upon size, concentration and shape of particles. According to Einstein [5] nanofluids were consisted of viscous fluid and spherical nanoparticles. Viscosity influences the pumping power and heat transfer rate.

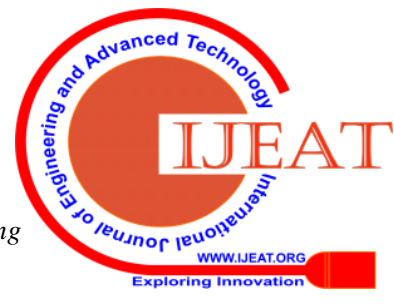




\section{Heat Transfer using Nanofluid}

Yan Liu et al. [6] conducted number of experiments to investigate the viscosity hybrid nanofluids and nanofluids consisting of $\mathrm{TiO}_{2}$, Ag and $\mathrm{Al}_{2} \mathrm{O}_{3}$ and engine oil.

They reported that hybrid nanofluid showed lower viscosity than single particle nanofluids. Generally, viscosity decreases with rise in temperature.

Different relations for the properties have been derived on the basis of experimental findings. Table 1 shows the equations and apparatus used by researchers for thermo physical properties. Terms used have their usual meanings.

Table- I: Thermo physical properties chart

\begin{tabular}{|l|l|l|l|}
\hline Property & Equation & Apparatus & Reference \\
\hline $\begin{array}{l}\text { Thermal } \\
\text { Conductivity }\end{array}$ & $k_{n f}=\frac{2 k_{b f}+k_{p}+2 \phi\left(k_{p}-k_{b f}\right)}{2 k_{b f}+k_{p}-\phi\left(k_{p}-k_{b f}\right)} k_{b f}$ & $\begin{array}{l}\text { KD Pro } \\
\text { KS-1 sensor }\end{array}$ & [7] \\
\hline Specific Heat & $C_{n f}=\frac{(1-\phi) \rho_{\mathrm{bf}} \cdot \mathrm{C}_{b f}+\phi \cdot \rho_{\mathrm{p}} \cdot \mathrm{C}_{\mathrm{p}}}{\rho_{n f}}$ & $\begin{array}{l}\text { Differential } \\
\text { Scanning } \\
\text { Calorimeter }\end{array}$ & [4] \\
\hline Viscosity & $\frac{\eta_{n f}}{\eta_{f}}=1+2.5(\phi), \quad \phi=\left(\frac{M_{p}}{M_{p}+M_{f}}\right) \times 100$ & $\begin{array}{l}\text { DV-III Ultra } \\
\text { Viscometer }\end{array}$ & [5] \\
\hline
\end{tabular}

Fluid properties are functions of temperature, concentration, size etc. Out of different fluid properties, thermal conductivity directly influences the heat transfer rate [1].

\section{MECHANISMS DESCRIBING THERMAL BEHAVIOUR}

\section{A. Brownian motion}

Nanoparticles suspended in base fluids exhibit motion of zig-zag nature which is known as Brownian motion. It is described by the mean velocity in a preferred direction. High temperature tends to increase this motion. Mallick et al. [8] estimated heat transfer rate and found excellent agreement with test data up to 5\% accuracy. However, some researcher found Brownian motion to be too slow to contribute in heat transfer enhancement [9, 10, 11]. Y. Cang et al. [12] compared the experimental and predicted data of test and reported over prediction and under prediction inaccuracy.

\section{B. Agglomeration}

Due to the forces of attraction, nanoparticles grouped together and form clusters. Size of the cluster affects the thermal conductivity [13]. Tendency for agglomeration increases as the size of nanoparticles is decreased [14]. According to Keblinski et al. [15] the clusters having loosely packed structures result in greater heat transfer enhancement than compact clusters. Heat transfer is enhanced up to some extent due to agglomeration [16]. However, the excessive agglomeration decreases the thermal conductivity. This may be due to sedimentation of clusters. To get stable suspensions these clusters are broken down by physical and chemical methods. Physical methods include ultrasonication and high pressure homogenization. Ultrasonication is of two types prob sonication and bath sonication. In chemical methods surfactants or functionalized particles are added to the suspensions to change surface properties of the particles. Hwang et al. [17] proposed a new method of using two micro-channels to break the clusters and get stable suspensions. In general agglomeration decreases the thermal conductivity and disturbs the stability. To overcome this problem, smaller size nanoparticles with low volumetric concentrations may be used.

\section{Thermophoresis}

Thermophoresis is produced due to the thermophoretic force which observed when a temperature gradient exist in nanofluids. Force of temperature gradient in temperature fields play important role. Nanoparticles in the hot region acquire higher kinetic energy due to high temperature and push the cold region nanoparticles. Thus, direction of the temperature gradient is opposite to the directions in nanoparticles flow $[18,19]$.

\section{Interfacial liquid layer}

This layer is formed between the surfaces of nanoparticles and liquid. It slips and enhances thermal conductivity [20, 21]. This enhancement is directly proportional to thickness of this layer [15]. Interfacial Liquid layer may be considered as a separate third component of nanofluid along with nanoparticles and base liquid.

\section{PARAMETERS AFFECTING THERMAL BEHAVIOUR}

\section{A. Temperature}

Temperature can affect the agglomeration by varying the motion of nanoparticles. Duangthongsuk et al. [22] conducted experiment with $\mathrm{TiO}_{2} /$ water nanofluids. They reported that rise in temperature and particle concentration resulted rise of heat transfer rate. Vajjha et al. [23] studied nanofluids at different temperatures. Linear relationship was reported between heat transfer and temperature. Syam Sundar et al. [24] conducted experiment with $\mathrm{Fe}_{3} \mathrm{O}_{4} / \mathrm{EG}$ and $\mathrm{Fe}_{3} \mathrm{O}_{4} /$ water $20^{\circ} \mathrm{C}$ to $60{ }^{\circ} \mathrm{C}$. They also reported the same relation.

\section{B. Volume concentration}

According to Masuda et al. [25] heat transfer rate and particle concentration show linear relationship in case of $\mathrm{Al}_{2} \mathrm{O}_{3}$ /water nanofluid. Lee et.al [26] also witnessed the linear relationship. Nanofluids containing the CNTs show a sudden increase even at small concentrations [27, 28]. Generally, heat transfer rate varies directly with volume concentration $[9,13]$.

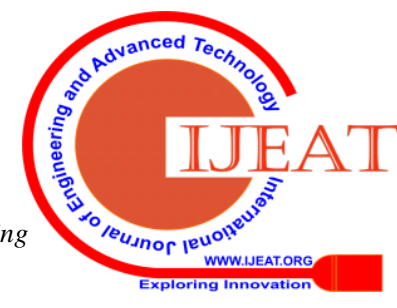


However, some researchers reported a nonlinear behaviour also [29, 30]. Agglomeration may be responsible for such nonlinear relationships.

\section{Size of nanoparticles}

In case of CNT, both diameter and length of tube are considered. Generally, shape of nanoparticles has been supposed to be spherical. Wang et al. [31] performed experiment on $\mathrm{CuO}$ based nanofluids having nanoparticles of different size. They reported that heat transfer rate varies directly with size of nanoparticles. Similar results were reported by other researchers also [32, 25]. Size also affects the viscosity of nanofluids which further affects heat transfer. He et al. [12] reported a linear relation between viscosity and size of nanoparticles in case of $\mathrm{TiO}_{2} /$ distilled water nanofluid whereas Namburu et al. [33] reported non-linear relationship. Michael Beck et.al [34] studied water and EG based seven nanofluids consisting of alumina nanoparticles of diameter varying from $8 \mathrm{~nm}$ to $282 \mathrm{~nm}$. They witnessed the decreased heat transfer in case of nanofluids containing nanoparticles of size more than 50nm.

\section{Shape of nanoparticles}

Choi et al. [35] studied water and EG based nanofluids consisting of spherical and cylindrical nanoparticles of SiC. They found more heat transfer enhancement through cylindrical particles (22.9\%) than spherical shaped (15.8\%). According to Murshed et al. [36] cylindrical particles are more efficient than spherical particles. Xie et al. [16] studied three different water based nanofluids consisting of CNTs, silver nanowires and copper nanowires. They reported that tube like particles improved heat transfer enhancement to large extent. Chen et al. [37] studied nanofluids consisting of spherical nanoparticles and cylindrical nanoparticles. They reported that difference in enhancement is not large. Hashemian et.al [38] replaced cylindrical tubes of heat exchanger with conical tubes of same weight. They found 54\% improvement in heat transfer. Generally, the cylindrical particles show more enhancement than spherical.

\section{E. Material of nanoparticles}

Different materials have different thermal conductivities. Out of $\mathrm{CuO}$ and $\mathrm{Al}_{2} \mathrm{O}_{3}$ heat transfer ability of alumina is high. However, heat transfer ability of nanofluids containing $\mathrm{CuO}$ particles was more than nanofluids containing $\mathrm{Al}_{2} \mathrm{O}_{3}$ particles [25]. This may be due to more agglomeration of $\mathrm{Al}_{2} \mathrm{O}_{3}$ nanoparticles than of $\mathrm{CuO}$.

Table- II: Summary of thermal conductivity enhancement

\begin{tabular}{|c|c|c|c|}
\hline Nanofluid & Parameter studied & Thermal conductivity Enhancement & Reference \\
\hline $\mathrm{Al}_{2} \mathrm{O}_{3} /$ water & volume concentration (4.3\%) & $32.4 \%$ & Masuda et al. [25] \\
\hline $\begin{array}{c}\mathrm{CuO} / \mathrm{EG}, \mathrm{CuO} / \text { water, } \\
\mathrm{Al}_{2} \mathrm{O}_{3} / \mathrm{EG} \text { and } \mathrm{Al}_{2} \mathrm{O}_{3} / \text { water }\end{array}$ & volume concentration (4\%) & $20 \%$ & Lee et al. [26] \\
\hline $\mathrm{CuO} / \mathrm{EG}$ & $\begin{array}{c}\text { size }(10 \mathrm{~nm}) \\
\text { volume concentration( } 0.3 \%)\end{array}$ & $40 \%$ & Eastman et al.[32] \\
\hline $\mathrm{Al}_{2} \mathrm{O}_{3} / \mathrm{EG}, \mathrm{Al}_{2} \mathrm{O}_{3} /$ water & Size $(8 \mathrm{~nm}-282 \mathrm{~nm})$ & increase up to size $50 \mathrm{~nm}$ beyond that start decreasing & Michael et.al [34] \\
\hline $\mathrm{CuO} / \mathrm{EG}$ & $\begin{array}{c}\text { Size }(23.6 \mathrm{~nm}) \\
\text { volume concentration (4\%) }\end{array}$ & $20 \%$ & Masuda et al.[25] \\
\hline $\begin{array}{c}\mathrm{Al}_{2} \mathrm{O}_{3} / \mathrm{EG}, \mathrm{CuO} / \mathrm{EG}, \\
\mathrm{Al}_{2} \mathrm{O}_{3} / \text { water,CuO/water }\end{array}$ & $\begin{array}{l}\text { temperature (298 K - 363K) } \\
\text { volume concentration }(10 \%)\end{array}$ & increased with rise in temperature and concentration & Vajjha et al. [23] \\
\hline MWCNTs/engine oil & volume concentration (4 \%) & $150 \%$ & Choi et.al [28] \\
\hline $\mathrm{TiO}_{2} /$ water & $\begin{array}{c}\text { temperature }\left(15^{\circ} \mathrm{C}-35^{\circ} \mathrm{C}\right) \\
\text { volume concentration }(0.2 \%-2 \%)\end{array}$ & $\begin{array}{c}26 \% \\
\text { increased with rise in temperature and concentration }\end{array}$ & $\begin{array}{l}\text { Duangthongsuk et } \\
\text { al.[22] }\end{array}$ \\
\hline Graphene nanosheets/water & $\begin{array}{l}\text { weight concentration } \\
(0.05,0.075 \& 0.1 \%)\end{array}$ & $\begin{array}{c}35.6 \% \text { at } 0.1 \text { wt. \% } \\
\text { Increased with concentration }\end{array}$ & Ghozatloo et al.[39] \\
\hline $\mathrm{Fe}_{2} \mathrm{O}_{3}-\mathrm{CuO} /$ water & volume concentration (0.5-1.5\%) & $21 \%$ at 1.5 vol. $\%$ & Tushar et al.[40] \\
\hline $\mathrm{TiO}_{2}-\mathrm{SiO}_{2} / \mathrm{EG}$-water & \begin{tabular}{|c|} 
different mixture ratio of \\
$\mathrm{TiO}_{2}-\mathrm{SiO}_{2}(20: 80,40: 60,50: 50,60: 40 \&$ \\
$80: 20)$ at $1 \%$ volume concentration \\
\end{tabular} & $35.32 \%$ at $40: 60$ mixture ratio and at $70^{\circ} \mathrm{C}$ & Hamid et al. [41] \\
\hline Graphene oxide/ water-EG & \begin{tabular}{|l|} 
weight concentration (0.01-0.1 \%) \\
\end{tabular} & $13.04 \%$ at $0.1 \mathrm{wt} . \%$ & Sajjad et al.[42] \\
\hline $\mathrm{TiO}_{2}$ - CNT/water & weight concentration (0.1-0.2 \%) & $38 \%$ at 0.2 wt. $\%$ & Megatif et al.[43] \\
\hline $\begin{array}{l}\text { Graphene nanoplatelets/ } \\
\text { Havoline - water }\end{array}$ & temperature (298K to $343 \mathrm{~K})$ & $73 \%$ & Vallejo et al. [2] \\
\hline Graphene nanoplatelets/water & $\begin{array}{c}\text { weight concentration } \\
(0.025,0.05,0.075 \text { and } 0.1 \%)\end{array}$ & $13-160 \%$ & $\begin{array}{l}\text { Sadeghinezhad et } \\
\text { al.[44] }\end{array}$ \\
\hline
\end{tabular}

It is observed that $\mathrm{Al}_{2} \mathrm{O}_{3}, \mathrm{TiO}_{2}, \mathrm{SiO}_{2}, \mathrm{CNT}, \mathrm{SiO} 2, \mathrm{CuO}, \mathrm{Fe}_{2} \mathrm{O}_{3}$ , $\mathrm{CuO}, \mathrm{CNT}$ and graphene oxide nanoparticles are generally used by the researchers. Out of different types of nanofluids carbon based nanofluids especially grapheme shows significant improvement in heat transfer [39, 44]. 


\section{Heat Transfer using Nanofluid}

This enhancement depends on thermo physical properties, thermal transport mechanisms and different parameters as discussed.

\section{F. Relative importance of parameters}

A number of properties and parameters were studied by the researchers making the nanofluid systems complex. Table 2 presents the summary of various studies. Elena et al. [45] made an attempt to identify the critical parameters and properties and prepared table 3 by summarizing general results found from the literature. The parameters and properties are listed columns and rows respectively. The weightage of $1.0,0.5,0.25$ and 0.0 was assigned to the parameters for strong, medium, weak and no dependence respectively on the basis of experimental findings [46].
Symbols used in table 3 have following meaning:

" $\uparrow$ " represents increase in property as parameter is increased

“ $\downarrow$ "represents decrease in property as parameter is increased

"S" represents strong dependence $(100 \%)$ of property on parameter.

" $\mathrm{M}$ " represents medium dependence $(50 \%)$ of property on parameter.

"W" represents weak dependence $(25 \%)$ of property on parameter." $\mathrm{N}$ " represents no dependence $(0 \%)$ of property on parameter.

"V" represents which may vary from system to system.

Table- III: Thermophysical properties chart [45]

\begin{tabular}{|c|c|c|c|c|c|}
\hline & Temperature & Vol. concentration & Size & Shape & Material \\
\hline Thermal conductivity & $\mathrm{M}$ & $\mathrm{S} \uparrow$ & $\mathrm{S} \uparrow$ & $\mathrm{M}$ & $\mathrm{M}$ \\
\hline Viscosity & $\mathrm{S}$ & $\mathrm{S} \downarrow$ & $\mathrm{S} \downarrow$ & $\mathrm{S}$ & $\mathrm{W}$ \\
\hline Stability & $\mathrm{V}$ & $\mathrm{W}$ & $\mathrm{S} \downarrow$ & $\mathrm{W}$ & $\mathrm{W}$ \\
\hline Specific heat & $\mathrm{W}$ & $\mathrm{S} \downarrow$ & $\mathrm{N}$ & $\mathrm{N}$ & $\mathrm{S}$ \\
\hline Heat transfer coefficient & $\mathrm{S}$ & $\mathrm{S} \uparrow$ & $\mathrm{S} \uparrow$ & $\mathrm{S}$ & $\mathrm{S}$ \\
\hline Relative Importance & $\mathbf{2 . 7 5}$ & $\mathbf{4 . 2 5}$ & $\mathbf{4 . 0 0}$ & $\mathbf{2 . 7 5}$ & $\mathbf{3 . 0 0}$ \\
\hline
\end{tabular}

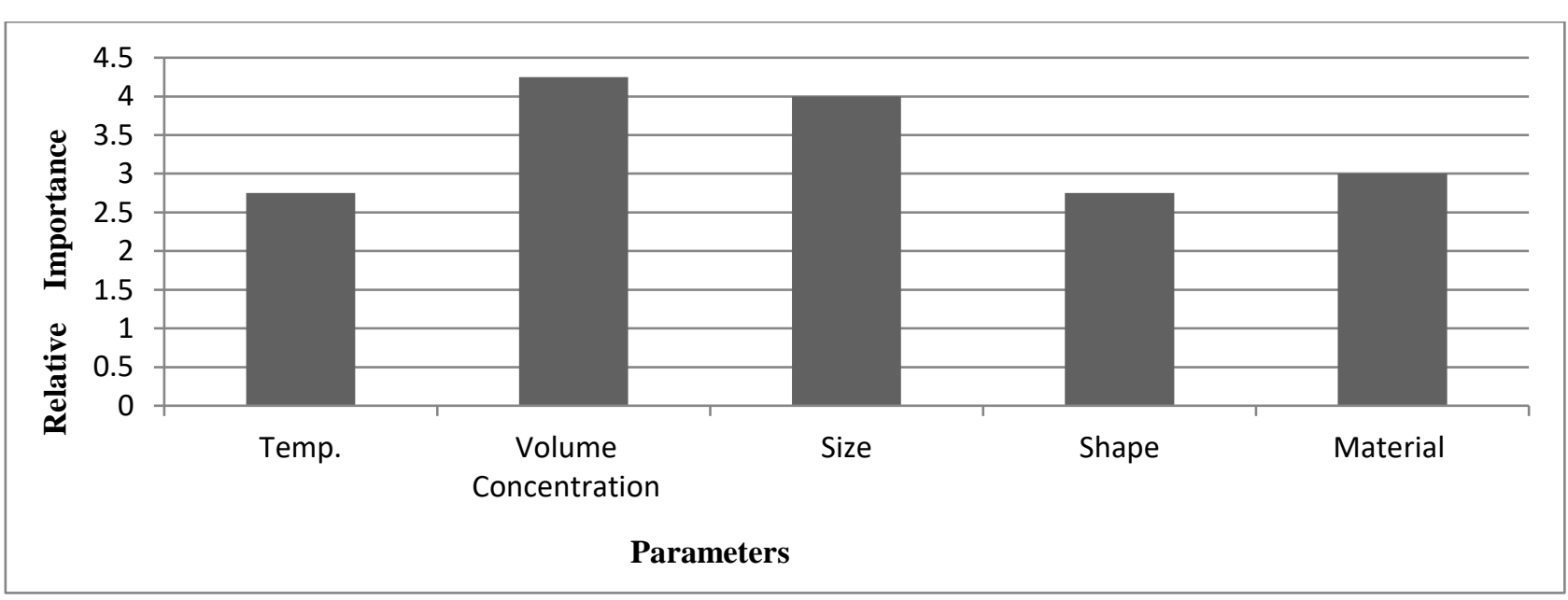

Fig.1. Relative importance of parameters

Relative significance of different parameter can be calculated by total scores as shown in table 3 . It is found that volume concentration and size are the dominant parameters. Fluid properties describing the heat transfer characteristics show strong dependence on both of the dominant parameters. This method may be used to manipulate properties by adjusting desirable parameters in order to improve heat transfer rate. Because no material possess all the desirable properties, so different materials having different desirable properties may be dispersed in base fluids to get hybrid nanofluids.

To study the effect of temperature, particle concentration and temperature on the thermal conductivity of nanofluid as well as to demonstrate the findings of previous studies of various researchers, an experiment was conducted by preparing water based $\mathrm{CuO}$ nanofluids.

\section{DESIGN OF EXPERIMENT}

\section{A. Preparation of nanofluid}

$\mathrm{CuO}$ nanoparticles of two different size (20nm and 50nm) were purchased from Nanoshel Company, Willmington United States. Two step method was used to prepare six samples of nanofluids at $0.1 \%, 0.5 \%$ and $1 \%$ weight concentration by dispersing specified amount of nanoparticles in distilled water without using any surfactant. Magnetic stirring was performed on the samples for one hour followed by ultrasonication for next three hour to get homogeneous mixture. Specifications as provided by the supplier are given in table 4.

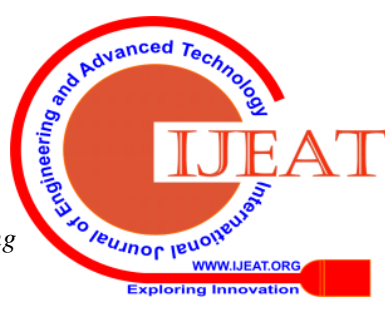


Table-IV: Composition of CuO nanoparticles.

\begin{tabular}{|l|l|}
\hline Parameter & Value \\
\hline Color & Black \\
\hline Morphology & Spherical \\
\hline Density & $0.79 \mathrm{~g} / \mathrm{cm}^{3}$ \\
\hline Weight & $79.54 \mathrm{~g} / \mathrm{mol}$ \\
\hline Purity & $99.9 \%$ \\
\hline $\mathrm{S}$ & $<0.01 \%$ \\
\hline $\mathrm{Si}$ & $<0.02 \%$ \\
\hline $\mathrm{Mg}$ & $<0.02 \%$ \\
\hline $\mathrm{Al}$ & $<0.01 \%$ \\
\hline
\end{tabular}

X-ray Diffraction (XRD) analysis and Field Emission Scanning Electron Microscopy (FESEM) of $\mathrm{CuO}$

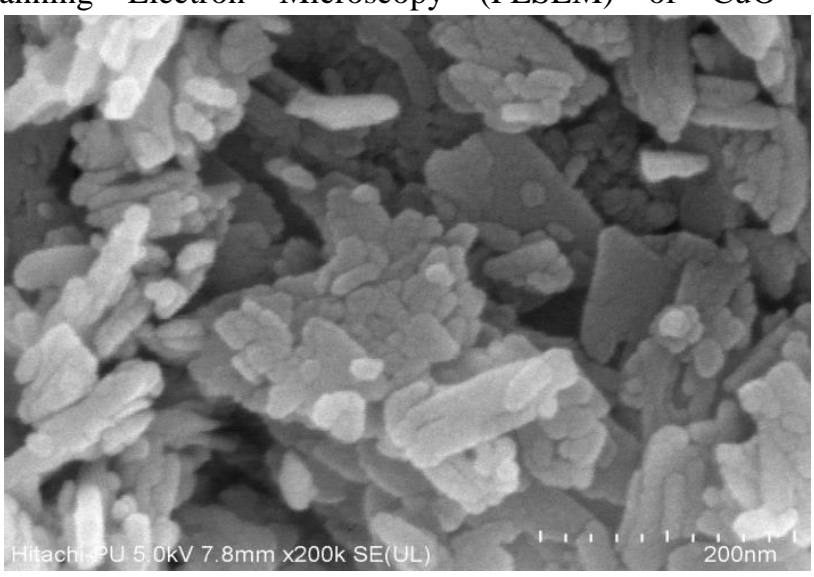

nanoparticles having 50nm size were performed to characterize material's morphology and size. XRD results showed that characteristic peaks located at different $2 \theta$ confirmed the structure of $\mathrm{CuO}$. The average crystal size using Debye Scherrer formula was found to be $48.7 \mathrm{~nm}$. FESEM images showed the average diameter to be $50 \mathrm{~nm}$. Nanoparticles were found to be spherical but tending to form clusters.

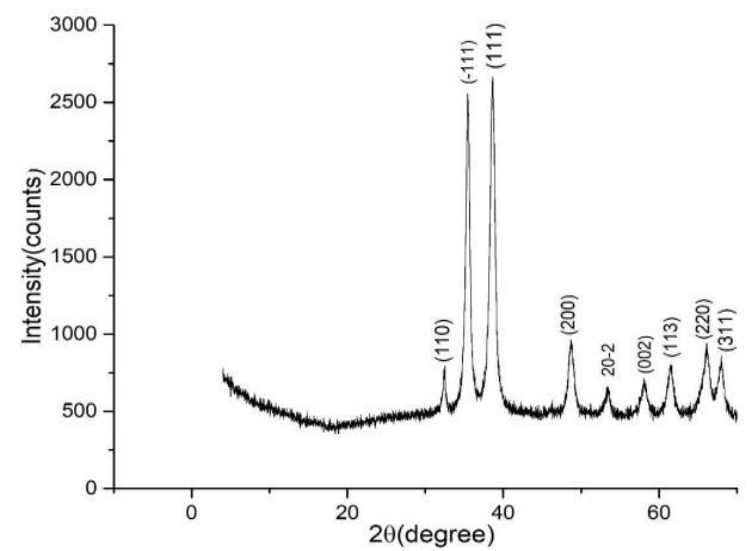

Fig. 2(a). FESEM image of CuO nanoparticles (50nm) (b). XRD of CuO nanoparticles (50nm)

Table-V: Mean thermal conductivity(W/mK) table of distilled water and nanofluids with various concentrations.

\begin{tabular}{|l|l|l|l|l|l|l|l|}
\hline \multirow{2}{*}{$\begin{array}{l}\text { Temperature } \\
\left({ }^{\circ} \boldsymbol{C}\right)\end{array}$} & \multirow{2}{*}{$\begin{array}{l}\text { Distilled water } \\
(\boldsymbol{W} / \mathbf{m K})\end{array}$} & \multicolumn{2}{|l|}{$\mathbf{0 . 1}$ wt. \% } & $\mathbf{0 . 5}$ wt. \% & \multicolumn{2}{l|}{ 1 wt. \% } \\
\cline { 3 - 8 } & Size, 20nm & Size, 50nm & Size, 20nm & Size, 50nm & Size, 20nm & Size, 50nm \\
\hline 30 & 0.598 & 0.625 & 0.610 & 0.648 & 0.619 & 0.660 & 0.631 \\
\hline 40 & 0.612 & 0.640 & 0.631 & 0.673 & 0.644 & 0.685 & 0.656 \\
\hline 50 & 0.620 & 0.667 & 0.660 & 0.695 & 0.682 & 0.762 & 0.723 \\
\hline
\end{tabular}

Table-VI: Thermal conductivity enhancement (in \% age) using different samples of nanofluid.

\begin{tabular}{|c|c|c|c|c|c|c|}
\hline \multirow{2}{*}{$\begin{array}{l}\text { Temperature } \\
\left({ }^{\circ} \mathrm{C}\right)\end{array}$} & \multicolumn{2}{|l|}{$0.1 w t . \%$} & \multicolumn{2}{|l|}{$0.5 w t . \%$} & \multicolumn{2}{|l|}{$1 \mathrm{wt.} \%$} \\
\hline & Size, $20 \mathrm{~nm}$ & Size, $50 \mathrm{~nm}$ & Size, $20 \mathrm{~nm}$ & Size, $50 \mathrm{~nm}$ & Size, $20 \mathrm{~nm}$ & Size, 50nm \\
\hline 30 & 4.51 & 2.0 & 8.36 & 3.51 & 10.36 & 5.51 \\
\hline 40 & 4.57 & 3.10 & 9.96 & 5.22 & 11.9 & 7.18 \\
\hline 50 & 7.58 & 6.45 & 12.09 & 10.0 & 22.90 & 16.61 \\
\hline
\end{tabular}

\section{B. Thermal conductivity measurement}

KD2 Pro thermal analyzer (Decagon Devices, USA) was used for the measurement along with a water bath to get randomly selected three different temperatures i.e. $30^{\circ} \mathrm{C}$, $40^{\circ} \mathrm{C}$ and $50^{\circ} \mathrm{C}$. Samples were kept inside the bath after getting the required temperature for further 10 minutes to achieve equilibrium. Three replicates of each reading were taken for all the samples and base fluid i.e. distilled water. Mean values were recorded in table 5.

\section{Results analysis}

Data of the experiment reveals that heat transfer is increased with increase in concentration of $\mathrm{CuO}$ nanoparticles in all the cases. The prepared nanofluids show almost linear increase in thermal conductivity with increase in temperature at all concentration. Enhancement in thermal conductivity of 1 wt. \% $\mathrm{CuO} /$ distilled water nanofluid containing small size(20nm) particles at $50^{\circ} \mathrm{C}$ is maximum i.e. $22.9 \%$ and at $30^{\circ} \mathrm{C}$ is $10.36 \%$ when compared with that of base fluid. This may be due to increased Brownian motion i.e. nanoparticles become more active with the rise in temperature and transfer more heat energy.

Heat transfer using $\mathrm{CuO} /$ distilled water nanofluid containing small size $(20 \mathrm{~nm})$ nanoparticles is greater than the heat transfer using nanofluids containing large size $(50 \mathrm{~nm})$ nanoparticles at the same particle concentration. It is found that small size nanoparticles affect thermal properties more. This shows the inverse relationship of heat transfer rate with with size of the particles.

Thus the experimental data validates the general trends of parameters in affecting heat transfer using nanofluids as witnessed by various researchers. 


\section{Heat Transfer using Nanofluid}

\section{CONCLUSION}

Heat transfer behavior of nanofluids is explored by addressing experimental studies performed by various researchers. To demonstrate the general findings related to the parameters affecting thermal conductivity, experimental results have been obtained by preparing and measuring thermal conductivity of $\mathrm{CuO} /$ distilled water nanofluids at different concentrations $(0.1 \%, 0.5 \%$ and $1 \%$ by weight $)$ and temperatures $\left(30^{\circ} \mathrm{C}, 40^{\circ} \mathrm{Cand} 50^{\circ} \mathrm{C}\right)$. The prepared nanofluids were found stable for a week without any surfactant.The main findings are listed below:

1. Nanofluids show more heat transfer as compare to base fluids. Thermal conductivity directly influences the heat transfer behaviour of nanofluid.

2. Agglomeration of nanoparticles is the significant mechanism which affects stability and heat transfer.

3. The volume concentration and size of nanoparticles are found to be relatively more significant in affecting the heat transfer.

4. Maximum enhancement of $22.9 \%$ in thermal conductivity is found in case of $1 \%$ weight concentration nanofluids consisting of small size $(20 \mathrm{~nm})$ nanoparticles at temperature of $50^{\circ} \mathrm{C}$.

4. Both concentration of particles and temperature shows linear relationship with thermal conductivity or heat transfer enhancement.

5. Heat transfer decreases with increase in size of the particles dispersed in base fluids.

6. Full understanding of heat transfer behavior of nanofluids is still lacking and lot of research is required aiming at practical applications in this area.

\section{REFERENCES}

1. Choi SUS.(1995). Developments and Applications of Non-Newtonian Flows. 66, pp. 99-105.

2. Vallejo, J.P.; Álvarez-Regueiro, E.; Cabaleiro, D.; Fernández-Seara, J.; Fernández, J.; Lugo, L.(2019). Thermophysical properties of funtionalized graphene nanoplatelet dispersions for improving efficiency in a wind turbine cooling system. Appl. Therm. Eng.

3. Nikulin, A.; Moita, A.S.; Moreira, A.L.N.; Murshed, S.M.S.; Huminic, A.; Grosu, Y.; Faik, A.; Nieto-Maestre, J.; Khliyeva, O.(2019). Effect of $\mathrm{Al}_{2} \mathrm{O}_{3}$ nanoparticles on laminar, transient and turbulent flow of isopropyl alcohol. Int. J. Heat Mass Transf. 130, pp. 1032-1044.

4. Xuan Y and Roetzel W. (2000). Int. Journal Heat Mass Transfer. 43, pp. 3701-3707

5. Einstein A (1906) Eine neue Bestimmung der Moleku ldimensionen Annalen Der Phys. 324(2), pp. 289-306.

6. Yan Liu,Deshun Yin, Mingyuan Tian, Xichen $\mathrm{Hu}$ 'Xuan Chen.(2018). Experimental investigation on viscosity of hybrid nanofluids made up of two kindes of nanoparticles mixed in engine oil, Micro and Nano Letters, vol.13(8), pp. 1197-1202

7. Maxwell JC. (1881). A treatise on electricity and magnetism $2^{\text {nd }}$ edition(UK:Oxford)

8. S.S. Mallick,A. Mishra and L. Kundan.(2013). An Investigation in to modelling thermal conductivity for alumina-water nanofluids. Journa of Powder Technology. 233, pp. 234-244.

9. Seok Pil Jang and S.U.S.Choi.(2004).Role of Brownian motion in the enhanced thermal conductivity of nanofluids Applied Physics Letters vol.84(21) (Energy Technology Divisional). pp. 4316-18

10. Prasher R, Bhattacharya P and Phelan PE 2005 Thermal conductivity of nanoscale colloidal solutions (nanofluids) Physics Review Letters 94(2) 025901

11. Koo J. and Kleinstreuer C 2005 Impact analysis of nanoparticle motion mechanisms on the thermal conductivity of nanofluids Int.

Communication Heat Mass Transfer 32(9)1-8.

12. He, Y, Jin, Y, Chen, H, Ding, Y, Cang, D, \& Lu. (2007). Heat transfer and flow behaviour of aqueous suspensions of $\mathrm{TiO}_{2}$ nanoparticles (nanofluids) flowing upward through a vertical pipe International Journal of Heat Mass Transfer. 50, pp. 2272-81

13. T.K. Hong, H.S. Yang and C.J. Choi. (2005). Study of the enhanced thermal conductivity of Fe nanofluids. Journal of Applied Physics. 97, article number- 064311

14. H. Chang, C. Jwo, P. Fan and S. Pai. (2007). Process optimization and material properties for nanofluid manufacturing. Int. J. Adv. Manuf. Tech. 34 (3), pp. 300-306

15. Keblinski P, Phillpot SR, Choi SUS and Eastman JA.(2002). Mechanisms of heat flow in suspensions of nano-sized particles (nanofluids). Int. J Heat Mass Transfer. 45(4), pp. 855-863

16. W. Yu, H. Xie, Y. Li and L. Chen .(2011). Experimental investigation on thermal conductivity and viscosity of aluminum nitride nanofluid. Particuology. 9 (2), pp. 187-191

17. Y. Hwang, J.K. Lee, J.K. Lee, Y.M. Jeong, S.i. Cheong, Y.C. Ahn and S.H. Kim .(2008). Production and dispersion stability of nanoparticles in nanofluids. Powder Tech.186 (2), pp.145- 153

18. J.A. Eastman, S.Phillpot, S. Choi and P. Keblinski. (2004). Thermal transport in nanofluids. Annu. Rev. Mater. Res. 34, pp. 219-246

19. $\mathrm{Yu} \mathrm{W}$. and Choi SUS. (2003). The role of interfacial layers in the enhanced thermal conductivity of nanofluids: a renovated Maxwell model. J. Nanopart. Res. 5(1-2), pp. 167-171

20. Yu W and Choi SUS .(2004). The role of interfacial layers in the enhanced thermal conductivity of nanofluids: a renovated Hamilton-Crosser model. J. Nanopart Res. 6(4), pp. 355-61

21. Ren Y, Xie H and Cai A. (2005). Effective thermal conductivity of nanofluids containing spherical nanoparticles. J. Phys. D Appl. Phys. 38(21), pp. 3958

22. Duangthongsuk, W.Wongwises, S. (2010). An experimental study on the heat transfer performance and pressure drop of TiO2-water nanofluids flowing under a turbulent flow regime. Int. J. Heat Mass Transf.53, pp. 334-344.

23. Vajjha, RS and Das DK.(2012). A review and analysis on influence of temperature and concentration of nanofluids on thermo physical properties, heat transfer and pumping power. Int. J. Heat Mass Transfer. 55, pp. 4063-4078

24. SyamSundar, L, Ravi Kumar, NT, Naik, MT and KV Sharma. (2012) Effect of full length twisted tape inserts on heat transfer and friction factor enhancement with $\mathrm{Fe}_{3} \mathrm{O} 4$ magnetic nanofluid inside a plain tube: An experimental study. Int. J. Heat Mass Transfer. 55, pp. 2761-2768

25. H. Masuda, A. Ebata, K. Teramae and N. Hishinuma. (1993). Alteration of thermal conductivity and viscosity of liquid by dispersing ultra-fine particles (dispersion of $\mathrm{Al}_{2} \mathrm{O}_{3}, \mathrm{SiO}_{2}$, and Ultra-fine particles), Netsu Bussei (Japan) 4 (4), pp. 227-233

26. Lee, S., Choi, S. U. S., Li, S., and J.A. Eastman .(1999). Measuring thermal conductivity of fluids containing oxide nanoparticles. Transactions of ASME Journal of Heat Transfer. 121, pp. 280-289

27. Biercuk, M.J., Llaguno, M.C., Radosavljevic, M., Hyun, J.K., Johnson, A.T., and J.E. Fischer.(2002). Carbon nanotube composites for thermal management Applied Physics Letters. 80, pp. 2767- 2772

28. Choi S.U.S., Zhang, Z.G., and P. Keblinski. (2004). Encyclopedia of Nanoscience and Nanotechnology.vol 6, ed H.S. Nalwa (Los Angeles, California: American Scientific Publishers) pp 757-773

29. Artus and R.G.C.(1996). Measurements of the novel thermal conduction of a prophoritic heat sink paste. Packaging and Manufacturing Part II(IEEE Transactions on Components. vol 19(3), pp. 601-604

30. Sandip kumar and Sonawane. (2011). An experimental investigation of thermo-physical properties and heat transfer performance of $\mathrm{Al}_{2} \mathrm{O}_{3}-$ aviation turbine fuel nanofluids. Applied thermal Engineering. 31, pp. 2841-49

31. Wang X., Xu X., Choi SUS (1999). Journal of Thermophysics and Heat Transfer. 13 (4), pp. 474-480

32. Eastman, J.A., Choi, U.S. Li, S., Thompson, L.J., and S. Lee. (1997). Enhanced thermal conductivity through development of nanofluids. Proc. of Symp. on Nanophase \& Nanocomposite Materials II. vol 457(Boston: Materials Research Society), pp. 3-11

33. Namburu P.,Kulkarni D.,Dandekar A. and D. Das (2007). Experimental investigation of viscosity and specific heat of silicon dioxide nanofluids. Micro Nano Lett. IET. 2(3), pp. 67-71 
34. Michael Beck, Yanhui Yuan, Amyn S. Teja and Pramod Warrier. (2009). The effect of particle size on the thermal conductivity of alumina nanofluids. Journal of nanoparticle research. 11(5), pp. 1129-1136

35. Choi SUS, Yu W, Hull JR, Zhang ZG and Lockwood FE (2001) Nanofluids for vehicle thermal management Society of Automotive Engineers (2001-01-1706), pp. 139-144

36. Murshed SMS, Leong KC and Yang C E.(2005). Int. J. Thermal Science. 44, pp. 367-373

37. H. Chen, S. Witharana, Y. Jin, C. Kim and Y. Ding.(2009). Predicting thermal conductivity of liquid suspensions of nanoparticles based on rheology Particuology. 7 (2),pp. 151-157

38. M. Hashemian, S. Jafarmadar, J. Nasiri, and H. Sadighi Dizaji. (2017). Enhancement of heat transfer rate with structural modification of double pipe heat exchanger by changing cylindrical form of tubes into conical form. Applied Thermal Engineering. vol. 118, pp. 408-417

39. Ghozatloo, A.; Rashidi, A.; Shariaty-niassar, M. (2014). Convective heat transfer enhancement of graphene nanofluids in shell and tube heat exchanger. Exp. Therm. Fluid Sci. 53, pp. 136-141.

40. Tushar gaidhane and Sameer bhosale. (2016). CFD analysis and experimental investigation of percentage heat transfer enhancement of CFHX with hybrid nanofluid as a coolant. International Journal of Mechanical and Production Engineering.

41. Hamid, K. A., Azmi, W. H., Nabil, M. F., \& Mamat, R. (2018) Experimental investigation of nanoparticle mixture ratios on TiO2-SiO2 nanofluids heat transfer performance under turbulent flow. International Journal of Heat and Mass Transfer, 118, pp. 617-627.

42. Sajjad, M., Kamran, M. S., Shaukat, R., \& Zeinelabdeen, M. I. M. (2018). Numerical investigation of laminar convective heat transfer of graphene oxide/ethylene glycol-water nanofluids in a horizontal tube. Engineering Science and Technology, an International Journal.

43. Megatif, L., Ghozatloo, A., Arimi, A., \& Shariati-Niasar, M. (2016) Investigation of laminar convective heat transfer of a novel TiO2-carbon nanotube hybrid water-based nanofluid. Experimental Heat Transfer. 29(1), pp. 124-138.

44. Sadeghinezhad, E.; Mehrali, M.; Tahan Latibari, S.; Mehrali, M.; Kazi, S.N.; Oon, C.S.; Metselaar, H.S.C. (2014). Experimental Investigation of Convective Heat Transfer Using Graphene Nanoplatelet Based Nanofluids under Turbulent Flow Conditions. Ind. Eng. Chem. Res.53, pp. 12455-12465.

45. Elena V Timofeeva, Wenhua Yu, David M France, Dileep Singh and Jules L Routbort. (2011). Nanofluids for heat transfer: An Engineering approach Nanoscale Res. Letters. 6(1), 182

46. Pugh S, Clausing D and Andrade R. (1996). Creating innovative products using total design. The living legacy of stuart Pugh. Reading (MA: Addison: Wesley Pub. Co).

\section{AUTHORS PROFILE}

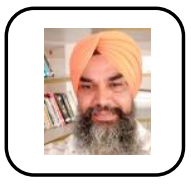

Jodh Singh He is working as Assistant Professor at Dr. SSB UICET, PU, Chandigarh, India. He has about 15 years teaching experience. He is M. Tech. in mechanical engineering and doing research in nanofluidics, welding, thermal and manufacturing engineering. He has presented many papers in conference proceedings and journals.

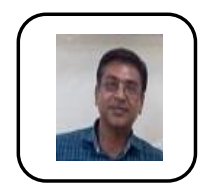

Munish Gupta He is Associate Professor in mechanical engineering at GJUST, Hissar, Haryana. India. His research area includes thermal engineering and nanofluids. He did his post graduation (with distinction) and PhD. from NIT Kurukshetra, Haryana, India. He has about 17 years of experience and many national and international publications to his credit.

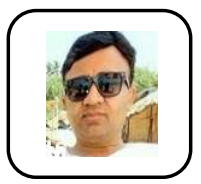

Rajesh Kumar He is Assistant Professor in mechanical engineering at UIET, PU, Chandigarh, India. He is doing research in area of CAD/CAM and nanotechnology. He did his graduation, Post graduation and $\mathrm{PhD}$ in mechanical engineering from PEC, Chandigarh, India. He has about 16 years of experience. He has many publications at national as well as international level to his credit.

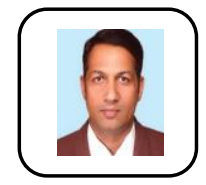

Harmesh Kumar $\mathrm{He}$ is Professor in mechanica engineering at UIET, PU, Chandigarh, India. He did his graduation, post graduation and Ph.D. with distinction. He is recipient of Gold medal for post graduation. He has about 26 years of experience. He is working in the field of nano fluidics, nano manufacturing and welding. $\mathrm{He}$ authored three books and has many international and national research publications to his credit. 